\title{
BIOGENIC VOLATILE ORGANIC COMPOUNDS IN THE AMBIENT AIR AND PLANT EMISSIONS OF A TASMANIAN NATIVE FOREST, AND THE RELATIONSHIP BETWEEN EMISSION RATES AND ESSENTIAL OIL CONTENT
}

\author{
by Joseph P. Hutchinson and Adrian J. Blackman
}

(with eight tables and one text-figure)

Hutchinson, J.P. \& Blackman, A.J., 2002 (31:xii): Biogenic volatile organic compounds in the ambient air and plant emissions of a Tasmanian native forest, and the relationship between emission rates and essential oil content. Papers and Proceedings of the Royal Society of Tasmania 136: 173-183. https://doi.org/10.26749/rstpp.136.173

ISSN 0080 4703. School of Chemistry, University of Tasmania, GPO Box 252-75, Hobart, Tasmania 7001, Australia.

The biogenic volatile organic compounds (VOCs) in the ambient air of the Hobart Air Shed and in the emissions from selected Tasmanian native trees and understorey shrubs were measured. The emission rates were then related to the plants' essential oils content, which had been extracted by hydro-distillation. The VOCs in the ambient air of native forests have not previously been studied in Australia. This study used multi-adsorbent cartridge adsorption/thermal desorption and Gas Chromatography-Mass Spectrometry. The type, quantity, source and variation of the VOCs were investigated.

The concentration of VOCs in the atmosphere surrounding vegetation in the Hobart Air Shed was determined. In all, 129 compounds of eight classes were detected. Of these, 11 compounds were National Pollutant Inventory substances and 32 were considered biogenic; however, this estimate is conservative. The concentration of total VOCs in these ambient air measurements varied between $4.43 \times 10^{-10} \mathrm{~g} \mathrm{~L}^{-1}$ and $3.04 \times 10^{-9} \mathrm{~g} \mathrm{~L}^{-1}$ depending on the site sampled and meteorological conditions. The relative standard deviation ranged between $3.5 \%$ and $51.8 \%$ in the dual air samples.

The emission rates of VOCs were determined for 14 plant species within the Hobart Air Shed, using an enclosure bottle technique. In all, 284 compounds of 10 classes were detected. Emission rates varied between $1.98 \times 10^{-8}$ and $5.43 \times 10^{-6} \mathrm{~g} \mathrm{~g}^{-1}$ (wet weight) $\mathrm{h}^{-1}$ depending on the species sampled and prevailing conditions. The relative standard deviation was estimated to be $31.1 \%$.

The VOC emission rate for the entire eucalypt forest in Tasmania was estimated as $8200 \mathrm{~kg} \mathrm{~h}^{-1}$ and for the Hobart Air Shed $59 \mathrm{~kg} \mathrm{~h}^{-1}$. The error could be as large as a factor of three. The essential oil compositions of the species examined were identified. Linear relationships between VOC oil concentration and emission rates were found in 10 of the 13 analyses.

Key Words: Volatile organic compound (VOC), biogenic emission rate, enclosure, essential oil, biogenic hydrocarbons, monoterpenes, sesquiterpenes.

\section{INTRODUCTION}

The chemistry of the atmosphere is strongly influenced by the ecological processes that control the emission of water and trace gases from plants. Went (1960) recognised that emissions of volatile organic compounds (VOCs) from foliage could significantly affect tropospheric chemistry through the processes that form atmospheric haze. Large quantities of VOCs are introduced into the atmosphere by anthropogenic and natural sources. The natural sources are the marine and terrestrial environments; this study focuses on VOCs produced by vegetation - the principal emitter of natural VOCs, responsible for possibly two-thirds of global VOC emissions (Muller 1992). Interest in the emission of VOCs has escalated to gain a better understanding of their role in shaping global tropospheric chemistry, forming regional photochemicaloxidants, balancing the global carbon cycle and producing organic acids that contribute to acidic deposition in rural areas (Fehsenfeld et al. 1992, Kesselmeier \& Staudt 1999).

Plants produce a variety of organic molecules for biochemical purposes, emitting those that are volatile into the atmosphere. About 400 VOCs are known to be emitted by plants; most are $\mathrm{C}_{10}-\mathrm{C}_{40}$ terpenoids (Hewitt \& Street 1992), including aldehydes, ketones, organic acids, alcohols, alkanes, alkenes and the $\mathrm{C}_{5}$ hemiterpene isoprene. There is a growing awareness that these compounds play an active role in the chemistry of the troposphere (Jacob \& Wofsy
1988, Seeds 1999). Isoprene and the monoterpenes affect atmospheric chemistry processes (Guenther et al. 1991). Biosynthetic pathways have been outlined (Crouteau 1987, Kreuzwieser et al. 1999), but the exact functions of the VOCs are unclear. Some are believed to act as pollinator attractors, herbicides and pesticides, while others may simply be waste or by-products with no physiological role (Monson et al. 1995). Isoprene is thought to form as a means of losing surplus energy under high light conditions and during membrane stabilisation (Hewitt \& Street 1992).

Given the number of plant species in the world, the available emission data of biogenic VOCs is sparse. Much of the work has been done in the Northern Hemisphere (Zimmerman 1979, Winer et al. 1992, Guenther et al. 1994, Andreani-Aksoyoglu \& Keller 1995, Konig et al. 1995, Street et al. 1997, Arnold et al. 1998, Wedel et al. 1998, Gomez et al. 1999, Isidorov et al. 1999, Kesselmeier et al. 2000, Lindfors et al. 2000) and has focused primarily on the emission of isoprene and the monoterpenes (Konig et al. 1995, Loretto et al. 1996a; b, Staudt et al. 1997, Steinbrecher et al. 1997). The measurement of VOCs emitted by individual species and ambient air data in Australia are limited to marine baseline data collected at Cape Grim on the northwest coast of Tasmania (Galbally et al. 1994-1995), emissions of VOCs (primarily oxygenated species) by pasture (Kirstine et al. 1998), emissions from 15 Eucalyptus species (He et al. 2000a) and their seasonal variation (He et al. 2000b), and isoprene emission from 
vegetation and hydrocarbon emissions from bushfires in tropical Australia (Ayers \& Gillett 1988). This is the first study to assess the VOC emissions of the native plant species chosen and the first in Australia to determine terrestrial ambient air concentrations of a broad range of these VOCs.

Until recently, global emission inventories of biogenic VOCs have been based predominantly on the emission rates of deciduous and coniferous forest types in North America (Guenther et al. 1995), as experimental data from other parts of the world are lacking. The weakness of this approach was demonstrated by Hewitt \& Street (1992) for the biogenic emissions of species in the United Kingdom. A global VOC emission database should ideally be set up on a genus level. The emission rates within a genus are similar and the use of genus emissions greatly simplifies modelling (Guenther 1997).

The National Pollutant Inventory Project was initiated in Australia on 1 July 1998 by Environment Australia. The nature of this project was to estimate the pollutants emitted into the air, land and water and compare this to the biogenic contribution of VOCs that take part in atmospheric processes such as the greenhouse effect and photochemical smog formation. The work described in this study relates to the determination of the nature, source and variation of biogenic VOCs in the Hobart Air Shed.

For the ambient air measurements, sites in the Hobart Air Shed with minimal anthropogenic VOC output were selected. One site (Chalet site) was sampled four times in three months April-June 2000, and other sites with different forest types were sampled. For the species enclosure measurements, species known to emit large quantities of VOCs were selected, together with the dominant species of the largest forest types in Tasmania. These include several eucalypt species other than Eucalyptus globulus, which has been studied elsewhere (Pio et al. 1997, Yassaa et al. 2000). The essential oils of these species were extracted by steam distillation and the compositions of the oils and emissions compared.

\section{METHOD}

\section{Sampling Sites}

Fifteen sampling trips were made to sites within the Hobart Air Shed in southern Tasmania (table 1). The GPS coordinates, time and environmental conditions for each sample were recorded (table 2). Supplementary weather conditions were obtained from the Bureau of Meteorology.

\section{Apparatus}

Air was sucked through adsorbent cartridges with a pump (Reciprotor, Type 506R) powered by a $430 \mathrm{cca}, 12$-volt battery (Exide, model 430D) with a solid-state inverter. A displacement bottle method was used to measure the flow rate of air sucked through an adsorbent cartridge attached to the suction of the pump by polyethylene tubing. Typically $30 \mathrm{~L}$ of air were sampled for the ambient air experiments and $10 \mathrm{~L}$ for the enclosure experiments.

For most of the ambient air measurements, dual samples were taken using a Y-tube joiner and identical polyethylene tube lengths with an adsorbent cartridge attached to each. The flow rate of each sample was measured individually and the summed value was equivalent to the total flow generated by the pump showing that there were no pressure leaks in the system used. The samples were taken about $1 \mathrm{~m}$ above ground level.

For the enclosure measurements a $10 \mathrm{~L}$ glass bottle was used. Teflon bags have been used for inert sampling apparatuses, but they are expensive and present problems when sampling in situ. For the sampling of many individual species, the bottle seemed preferable, as it is rigid, portable and easily set up. The bottle had an $8-\mathrm{cm}$ opening at the top where the branch of the plant being investigated entered the bottle and a 4-cm NS 23 ground-glass opening at the bottom where the NS 14/23 reducer was attached to a Schott Teflon-coated adjustable thermometer housing. This formed an airtight seal around the adsorbent cartridges. Care was taken to minimise handling the foliage and not damage the plant. Polyethylene plastic ensured an airtight seal around the top of the enclosure and the branch. Polyethylene tubing was attached to the pump and the cartridge. An adsorbent tube was placed in an airtight sheath made in the polyethylene plastic. The ambient air entering the apparatus was scrubbed with an adsorbent tube. To ensure that no ambient air was collected by the second adsorbent cartridge, the system was flushed by three volumes of the enclosure bottle $(30 \mathrm{~L})$ before the second adsorbent tube was put into place.

\section{Adsorbent Cartridges}

The glass cartridges were $78.6 \mathrm{~mm}$ long, $6.0 \mathrm{~mm}$ in external diameter and $3.0 \mathrm{~mm}$ in internal diameter. A restriction was placed in the glass cartridge to stop the pump removing the packing. Each cartridge typically contained $0.02 \mathrm{~g}$ of Carbosieve S-III 60/80 mesh and $0.10 \mathrm{~g}$ of Tenax TA $60 / 80$ mesh purchased from Supelco. Glass wool was used to

TABLE 1

Coordinates of the sampling sites as measured by a Global Positioning System (GPS) and the altitudes as taken from topographical maps

\begin{tabular}{lcccccc}
\hline & Howrah & Rokeby Hills & Meehan Range & Chalet & Springs & Radford Track \\
\hline Southern Coordinate & $42^{\circ} 53.210^{\prime}$ & $42^{\circ} 53.543^{\prime}$ & $42^{\circ} 50.071^{\prime}$ & $42^{\circ} 53.333^{\prime}$ & $42^{\circ} 54.889^{\prime}$ & $42^{\circ} 54.927^{\prime}$ \\
Eastern Coordinate & $147^{\circ} 24.483^{\prime}$ & $147^{\circ} 25.048^{\prime}$ & $147^{\circ} 24.635^{\prime}$ & $147^{\circ} 14.179^{\prime}$ & $147^{\circ} 14.935^{\prime}$ & $147^{\circ} 15.577^{\prime}$ \\
Altitude $(\mathrm{m})$ & 40 & 80 & 140 & 980 & 720 & 520 \\
& & & & & & \\
\hline
\end{tabular}


separate the adsorbent packing. Cartridges were cleaned for $40 \mathrm{~min}$ at $290^{\circ} \mathrm{C}$ with nitrogen gas flowing at a rate of $15 \mathrm{~mL}$ $\min ^{-1}$. Each cartridge was sealed with Swagelok stainless steel endcaps fitted with Teflon ferrules.

\section{Analytical Procedures}

The adsorbent cartridges were placed into the injector port of the gas chromatograph (GC) and fitted with a rubber oring to form an airtight seal. Water was removed from the sample by dry gas purging. The precolumn was placed in a liquid nitrogen cryotrap to focus the VOCs before separation on the HP-1 capillary column. The VOCs in the sample were identified by their mass spectra and their respective amounts calculated from the TIC integration counts and external standards. The GC was a Hewlett Packard 5890 Benchtop Gas Chromatograph and the detector a Hewlett Packard 5970 Series Mass Selective Detector.

The nitrogen flow rate was $4 \mathrm{~mL} \mathrm{~min}{ }^{-1}$ for VOC separation. The detector and thermal desorption program were started manually when the precolumn was removed from the cryotrap after the desorption period had elapsed. The data system used was HP1034C MS Chemstation Software. The GC oven temperature program was initially $20^{\circ} \mathrm{C}$, which increased by $6^{\circ} \mathrm{C} \mathrm{min}^{-1}$ to $290^{\circ} \mathrm{C}$. The MS was operated in the positive ion, electron impact, scanning mode from 35-400 AMU at intervals of $0.58 \mathrm{~s}$ with the electron multiplier at $-1.8 \mathrm{kV}$. A splitless method was used to ensure all of the sample was counted by the detector. VOCs were identified with the aid of the commercial NIST and the in-house mass spectral libraries of the Central Science Laboratory.

\section{Water Removal}

A $60-\mathrm{cm}, \mathrm{DB}-1$ phase $(0.15 \mu \mathrm{m}$ film thickness $)$ megabore precolumn, was attached to the HP-1 crosslinked methylsiloxane $(0.52 \mu \mathrm{m}$ film thickness $)$ column of $25 \mathrm{~m}$ length, $0.32 \mathrm{~mm}$ internal diameter. The precolumn was used to stop the liquid nitrogen cryotrap from damaging the $\mathrm{HP}-1$ column and the wider bore reduced ice blockage when placed in the cryotrap. To remove water before thermal desorption, each sample was purged with nitrogen gas $\left(10 \mathrm{psi}, 30 \mathrm{~mL} \mathrm{~min}{ }^{-1}\right)$ for three minutes at $99^{\circ} \mathrm{C}$. This allowed the desorption of water only; small, volatile compounds such as propane were still detected in equal proportions in replicate studies.

\section{Cryotrap Focusing of VOCs}

The precolumn was placed in a liquid nitrogen cryotrap to focus the thermally desorbed sample. The cartridge in the injector port was desorbed at a temperature of $220^{\circ} \mathrm{C}$ for 15 min at a flow rate of $12 \mathrm{~mL} \mathrm{~min}^{-1}$. The nitrogen flow was continually checked for ice blockage in the precolumn.

\section{Controls, Breakthrough and Error}

For the ambient air analysis, replicates were made by using two cartridges simultaneously. An adsorbent cartridge that had been treated in the same manner as those used for VOC collection was always carried with the experimental cartridges to act as the blank. For the enclosure experiments, replicates could not be performed simultaneously. However, the same species was analysed consecutively under similar conditions. Error was calculated on the total sample amount and also for the individual compounds. For the enclosure experiments, the control was a branch without foliage in the enclosure. Breakthrough volumes were monitored by placing two adsorbent cartridges in series indicating whether the VOC collection method was quantitative. A suburban air sample was taken to assess whether the VOCs from the naturally vegetated sites differed from those at a potentially polluted suburban site.

\section{Plant Species}

Fourteen of the most common species found in the dry sclerophyll, wet sclerophyll and subalpine regions that dominate the Tasmanian vegetation (Reid et al. 1999) were selected: Eucalyptus leucoxylon, E. viminalis, E. johnstonii, Epacrisimpressa, Phebaliumsquameum, Tasmannialanceolata, Olearia phlogopappa, Leptospermum lanigerum, Ozothamnus antennaria, Correa lawrenciana, Pomaderris apetala, Bedfordia salicina, Acacia dealbata and Zieria arborescens. The samples, which were growing at the chosen sample sites within a 20 $\mathrm{km}$ radius of Hobart, Tasmania, were identified by the Tasmanian Herbarium.

\section{Standards}

An internal standard is the standard of choice for gas chromatography (Schomburg 1990). However, an external standard mixture made up at six concentrations covering the range of VOC concentrations that were present in the ambient air and enclosure measurements was used as it was not known which compounds would be present in the samples taken (possibly up to 100) and spiking internal standards onto the sorbent catridges was not practical. The standards are listed in table 3; the solvent was HPLC/GC grade $n$-hexane solution (Mallinckrodt, 95\%).

The standard mixtures were analysed on the GC-MS each time the samples were run to eliminate error from fluctuation in the GC-MS response. The standard curves spanned the different response factors in this study. An average was taken of these responses for quantitative purposes and the associated error was noted. For separation, the GC-MS injector was kept at $260^{\circ} \mathrm{C}$ and the HP7673 autosampler was used to make a $10 \mu \mathrm{L}$ injection. The temperature was held at $20^{\circ} \mathrm{C}$ for $3 \mathrm{~min}$, then increased by $6^{\circ} \mathrm{C} \min ^{-1}$ to $135^{\circ} \mathrm{C}$, giving a total run time of $27.17 \mathrm{~min}$. The nitrogen gas column flow used was $4.6 \mathrm{~mL} \mathrm{~min}^{-1}$.

\section{Essential Oil Analysis}

The foliage used in the enclosure experiments was brought back to the laboratory, weighed and steam-distilled by Boland's (1991) method to obtain the essential oil. Distillation typically took between 24 and $48 \mathrm{~h}$. After the organic phase was collected and dried, the dichloromethane was evaporated to leave the essential oil. The oil was diluted volumetrically in hexanes for analysis by GC-MS.

The injector was held at $220^{\circ} \mathrm{C}$. The oven was held at 
$60^{\circ} \mathrm{C}$ for $2 \mathrm{~min}$ and then increased by $6^{\circ} \mathrm{C} \mathrm{min}-1$ to $240^{\circ} \mathrm{C}$, at which point the rate was increased to $30^{\circ} \mathrm{C} \mathrm{min}{ }^{-1}$ until $290^{\circ} \mathrm{C}$ was reached. The total run time was $38.67 \mathrm{~min}$. The nitrogen gas column flow used was $4.6 \mathrm{~mL} \mathrm{~min}{ }^{-1}$.

\section{Solid-Phase Microextraction (SPME) Analysis}

The 100micron 24-gauge polydimethylsiloxane SPME fibre purchased from Supelco was desorbed at $200^{\circ} \mathrm{C}$ on the GCMS before sampling. The fibre was housed in an airtight sheath and exposed for two hours. It was then placed directly into the injector port at $200^{\circ} \mathrm{C}$ following Betts's (2000) method. The temperature program for the $\mathrm{GC}$ oven was $5^{\circ} \mathrm{C}$ for $3 \mathrm{~min}$, increasing by $6^{\circ} \mathrm{C} \mathrm{min}^{-1}$ to $280^{\circ} \mathrm{C}$. This temperature was maintained for $5 \mathrm{~min}$, giving a total run time of $53.83 \mathrm{~min}$. The flow rate of the nitrogen gas column was $5 \mathrm{~mL} \mathrm{~min}^{-1}$.

\section{RESULTS AND DISCUSSION}

\section{Ambient Air Analysis}

Table 2 shows the sampling dates, type, conditions and the total VOCs found in $\mathrm{g} \mathrm{L}^{-1}$ and the error associated with these measurements for each site. The average deviations for all individual compounds in a particular sample were below $52 \%$, some as low as $12.8 \%$, showing reasonable reproduciblity keeping in mind the uncertainty involved in quantifying trace volatiles in the air. Similar methods in the literature reported errors typically between $40 \%$ and $80 \%$ (Guenther et al. 1996, Wedel et al. 1998), which is comparable to the error found in this study. The maximum deviation from the function used to describe the specific response of the detection system was $53 \%$, but the error was typically much lower than this. This is thought to be the largest source of error involved in the experimental technique.

\section{Trends and Variation in Ambient Air Results}

The total VOC concentrations found are shown in table 2. Temperature is the main variable that influences emission of terpenes (Fehsenfeld et al. 1992). Some trends can be established from the data sampled over several months from the Chalet site. Figure 1 shows a relationship between temperature and VOC air concentration but no clear relationship between humidity and VOC air concentration.

The Chalet site was classified as a subalpine woodland dominated by species such as Tasmanian snow gum (Eucalyptus coccifera), urn gum (E. urnigera) and occasionally myrtle (Nothofagus cunninghamii) (Wellington Park Management Trust 1996) and various understorey species. The Springs site was classified as wet sclerophyll dominated by $E$. johnstonii and various understorey species (Reid et al. 1999). The Radford Track site was classified as a wet eucalypt forest dominated by E. obliqua and E. regnans and various understorey species (Reid et al. 1999). The Meehan Range and Rokeby Hill sites were both dry sclerophyll sites, dominated by $E$. viminalis, $E$. obliqua, E. tenuiramis and various understorey shrubs (Reid et al. 1999).

\section{VOCs Detected at the Sampling Sites}

A total of 129 VOCs were detected by comparing the mass spectra of the compounds separated by gas chromatography to known spectra in the mass spectral libraries. This included 11 National Pollutant Inventory compounds (DPIWE 1998) that are notifiable substances to the inventory as of 1 July 1998. However, many monoterpenes and sesquiterpenes cannot be identified with certainty from their mass spectra alone. Thus, the compounds other than those used as standards in table 3 are tentatively identified.

Compounds that were widely represented among the sites were acetophenone, piperitone, benzophenone, 6,10dimethyl-5,9-undecadien-2-one, acetic acid, pentane, butane, isobutane, isopentane, undecane, hexadecane, pentadecane, nonane, decane, tridecane, tetradecane, nonadecane, dodecane, 2-undecen-2-ol, p-menth-2-en-1ol, 2-decen-1-ol, cineole, benzaldehyde, octanal, nonanal, decanal, undecanal, 2-tridecenal, 1,2,3-trimethylbenzene, 1-ethyl-2-methylbenzene, benzene, toluene, xylene, naphthalene and cymene.

Isoprene is typically present in biogenic VOC samples in the literature. However, it was not observed in any of the air or enclosure measurements taken as part of this study.

This may be because isoprene production requires several consecutive days of a threshold temperature (about $20^{\circ} \mathrm{C}$ ) to start (Sharkey \& Loretto 1993). The temperatures and light conditions during the course of this study were probably too low for isoprene synthesis to be detected. Other important trends observed were:

1. More monoterpenes were present at nightfall, which may reflect decreased winds, a decreased atmospheric mixing height or both, which has been observed previously.

2 . The main biogenic VOCs found at most sample sites were those dominating the Eucalyptus essential oils (i.e. cineole, piperitone, p-menth-2-en-ol, cymene and 6,10 dimethyl-5,9-undecadiene-2-one) (Boland et al. 1991). The VOCs present in the largest concentrations were generally acetic acid, benzaldehyde, cymene, cineole, acetophenone, nonanal and decanal. Acetophenone and benzaldehyde are likely to be an artefact of the reaction of low molecular weight polymers and impurities in the Tenax with ozone (Cao \& Hewitt 1994).

\section{Individual Compound Concentration at the Chalet Site}

The compounds present in all the Chalet samples were piperitone, cineole, nonanal, decanal, cymene and acetophenone. In three of the four samples $p$-menth-2-enol and $p$-menth-3-en-ol were also present. The concentration of these compounds was compared with respect to the temperature and humidity at the time sampled. Table 4 shows the variation with temperature. No relationship was found with humidity.

The VOCs increased their ambient air concentrations when the temperature increased, as shown in table 4 . The $R^{2}$ values ranging from $0.67-0.99$ indicate reasonable linear relationships, but some other non-linear function cannot be disproved. It was found that the $\mathrm{Y}$-intercept, which represents the minimum temperature in degrees Celsius at which the compounds will be detected in the air, ranged between $6.6^{\circ} \mathrm{C}$ for acetophenone and $10^{\circ} \mathrm{C}$ for cymene. 
TABLE 2

Sample dates, times, conditions and the total VOC concentrations in ambient air and the total VOC emission rates for the enclosure experiments, indicating the errors involved

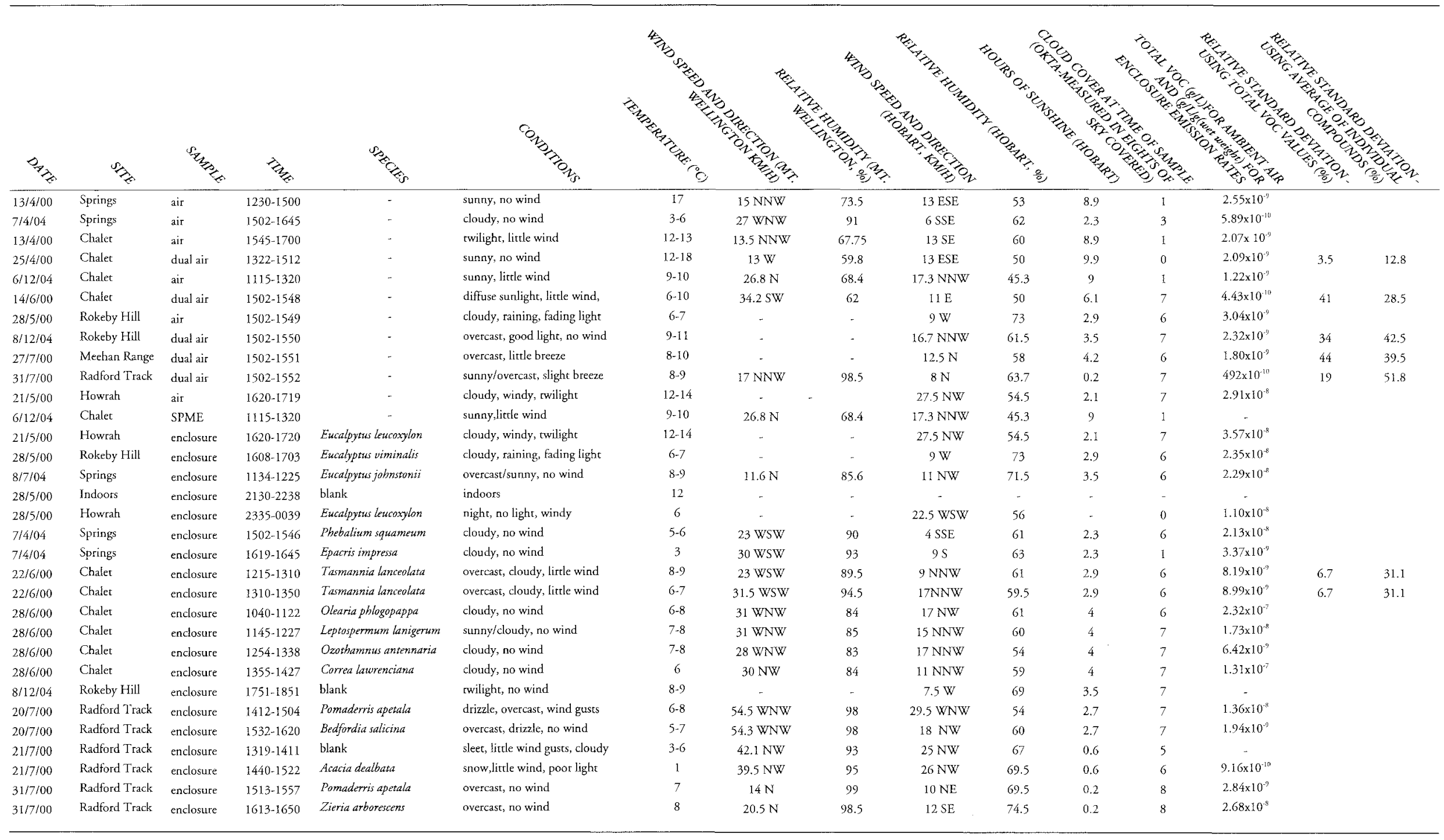




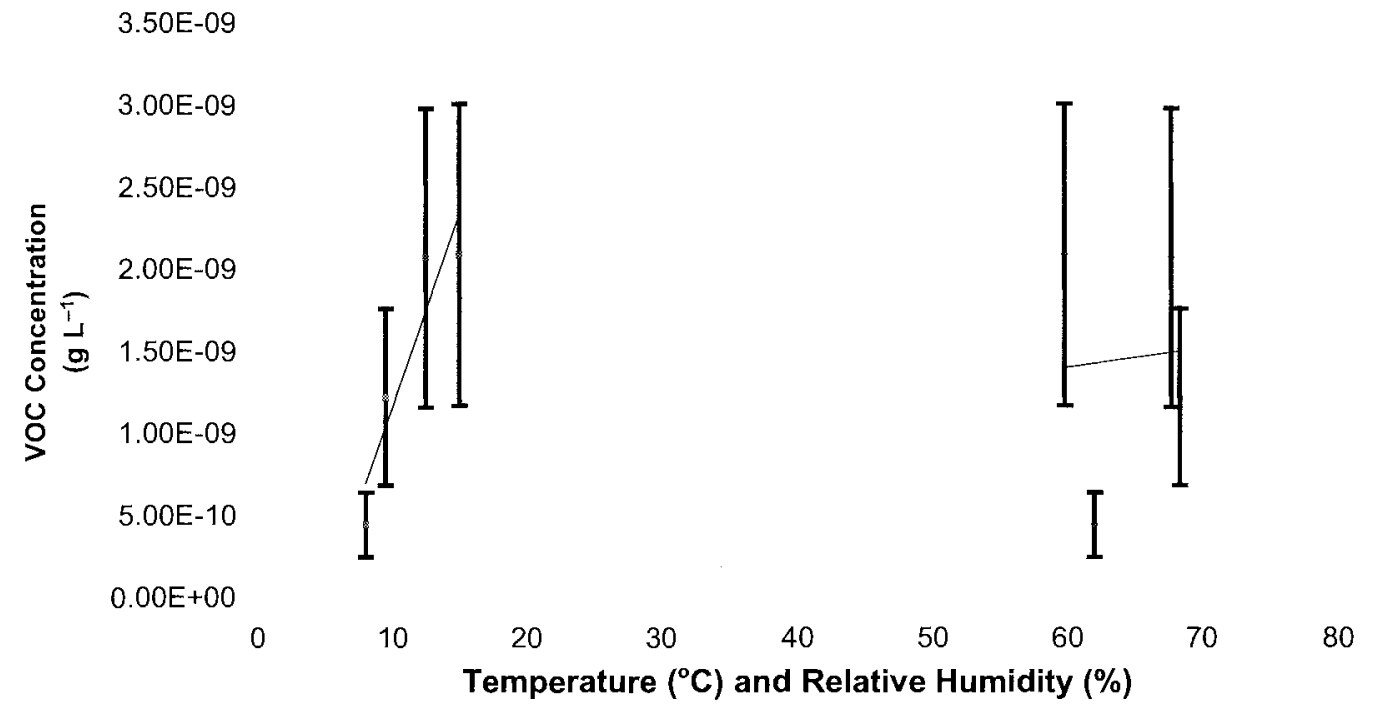

FIG. 1 - Variations of total VOC ambient air concentration $\left(g L^{-1}\right)$ for temperature (left) and humidity (right). (A) The trendline for the temperature variation is represented by $Y=\left(\begin{array}{lll}2 & x & 10^{-10}\end{array}\right) \times-\left(\begin{array}{lll}1 & 10^{-9}\end{array}\right)$ with an $R^{2}$ value of 0.86.(B) The trendline for the humidity variation shows a poor fit with an $R^{2}$ value of 0.01 .

TABLE 3

Standards used in this study

\begin{tabular}{llllll}
\hline Reagent & Supplier & Grade & Reagent & Supplier & Grade \\
\hline acetophenone & BDH & $99 \%$ & a-pinene & Aldrich & $98 \%$ \\
benzene & M and B & Distilled & limonene & Aldrich & $96 \%$ \\
toluene & BDH & LR & propanal & Ajax & AR \\
xylene & BDH & $99 \%$ & acetone & BDH & AR \\
geraniol & Koch Light & $99 \%$ & 1,8 -cineole & Aldrich & $95 \%$ \\
menthol & Hopkins and Williams & LR & heptane & Ajax & AR \\
$\begin{array}{l}\text {-cymene } \\
\text { ethyl acetate }\end{array}$ & Aldrich & $99 \%$ & dodecane & Sigma & $99 \%$ \\
& BDH & AR & terpenen-4-ol & Fritzche-D and O & $95 \%$ \\
\hline
\end{tabular}

TABLE 4

Graphical data found from VOCs ambient air concentration $\left(\mathrm{g} \mathrm{L}^{-1}\right)$ at Chalet site vs temperature $\left({ }^{\circ} \mathrm{C}\right)$

\begin{tabular}{|c|c|c|c|c|c|}
\hline Compound & $\begin{array}{c}\text { Trendline } \\
\text { equation } \mathrm{Y}=\end{array}$ & $\begin{array}{c}\mathrm{R}^{2} \\
\text { value }\end{array}$ & Compound & $\begin{array}{l}\text { Trendline } \\
\text { equation } \mathrm{Y}=\end{array}$ & $\begin{array}{c}\mathrm{R}^{2} \\
\text { value }\end{array}$ \\
\hline $\begin{array}{l}\text { acetophenone } \\
\text { decanal } \\
\text { cymene } \\
\text { nonanal }\end{array}$ & $\begin{array}{l}\left(4 \times 10^{-11}\right) \times-\left(3 \times 10^{-11}\right) \\
\left(3 \times 10^{-11}\right) \times-\left(2 \times 10^{-10}\right) \\
\left(2 \times 10^{-11}\right) \times-\left(7 \times 10^{-11}\right) \\
\left(2 \times 10^{-11}\right) \times-\left(2 \times 10^{-10}\right)\end{array}$ & $\begin{array}{l}0.74 \\
0.80 \\
0.74 \\
0.83\end{array}$ & $\begin{array}{l}\text { cineole } \\
p \text {-menthen-3-ol } \\
p \text {-menthen-2-ol } \\
\text { piperitone }\end{array}$ & $\begin{array}{c}\left(1 \times 10^{-11}\right) \times-\left(5 \times 10^{-11}\right) \\
\left(8 \times 10^{-12}\right) \times-\left(5 \times 10^{-11}\right) \\
\left(7 \times 10^{-12}\right) \times-\left(4 \times 10^{-11}\right) \\
\left(4 \times 10^{-12}\right) \times-\left(2 \times 10^{-11}\right)\end{array}$ & $\begin{array}{l}0.67 \\
0.99 \\
0.63 \\
0.69\end{array}$ \\
\hline
\end{tabular}


The similarity of these trendlines may suggest that similar biological volatilisation mechanisms that govern the release of biogenic VOCs into the air and atmospheric degradation processes are occurring for a variety of different biogenic VOCs measured in this study.

Cymene, cineole, $p$-menthen-2-ol, p-menthen-3-ol and piperitone are all biogenic mevalonate metabolites produced by plants (Boland et al. 1991). Acetophenone is a shikimate metabolite produced by plants (Mann 1987) and has also been noted in the literature as an artefact (Cao \& Hewitt 1994). Aldehydes such as nonanal and decanal were found in the oil analyses performed in this and other studies (Hendricks et al. 1978, Alonzo et al. 2000). Nonanal has been found in the emissions from slashed grass (Kirstine $e t$ al. 1998) and other species (Konig et al. 1995), but aldehydes were not found in the enclosure experiments in this study. Possibly aldehydes are emitted biogenically by species other than those sampled.

No anthropogenic compounds such as benzene or toluene (Pankow et al. 1998, Muraleedharan et al. 2000) were detectable in any of the air samples, so differences in variation between biogenic and anthropogenic compounds with regard to temperature could not be established. In future work, if the expected difference (Andreani-Aksoyoglu \& Keller 1995) between biogenic and anthropogenic variation of compounds as a function of temperature is found, this could be used as a definitive means for establishing whether a given VOC is in fact of biogenic origin.

Compounds that were structurally similar tended to have similar trendlines, which is shown by nonanal and decanal, and $p$-menthen-2-ol and p-menthen-3-ol in table 4 . This is a result of atmospheric lifetimes of the biogenic VOCs depending strongly on their structure.

The individual trends of increasing VOC air concentration with increasing temperature are in agreement with the total VOC trend for temperature at the Chalet site. The value for this trend was $Y=\left(2 \times 10^{-10}\right) \times-\left(1 \times 10^{-9}\right)$ where the VOC air concentration is zero at $5^{\circ} \mathrm{C}$ (the $\mathrm{Y}$ intercept). Note that the gradient for the total VOC should equal the sum of the individual gradients, as this represents the total VOC air concentration. The sum of the gradients for the compounds investigated is $1.4 \times 10^{-10}$, which is the major portion of the total VOC detected.

\section{Use of Solid-Phase Microextraction for the Ambient Air Analysis of VOCs}

Solid-phase microextraction has been used previously only for analysis of the headspace of a closed environment where the VOCs can accumulate and concentrations are much higher than those observed in the ambient air (Betts 2000). In this study the method proved to be too insensitive for analysis of ambient air VOCs. However, it might be a means of confirming the compounds present in enclosure measurements where the VOC concentrations are much greater.

\section{Suburban Air Sample}

The suburban air sample taken at Howrah showed that the alkanes, aldehydes and ketones present are probably not emitted from natural vegetation. This was taken into consideration in forming the subset of biogenic compounds in the air at the sample sites chosen. The suburban air sample had an abundance of straight-chain ketones, aldehydes and alkanes that were not found in any of the other samples. These may be due to pollutants in the case of the alkanes or to the introduced vegetation typical of suburban areas, including cut grass, which emits a variety of oxygenated VOCs (Kirstine et al. 1998).

\section{Enclosure Air Analysis}

The compounds tentatively identified by GC-MS were the terpenes $\alpha$-pinene, myrcene, carene, camphene, aphellandrene, 2,6,6-trimethylbicyclo(3.1.1.)hept-2-ene, limonene, longifolene, $\alpha$-gurjunene, aromadendrene, alloaromadendrene, caryophyllene, $\alpha$-copaene, $\beta$-cubebene, cymene and cineole. Sharkey \& Loretto (1993) found that the capacity of isoprene emission disappears from leaves below $20^{\circ} \mathrm{C}$ and strong light is required for isoprene to be synthesised. Isoprene was not observed during the winter sampling period of this study (sample dates are given in table 2). Evans et al. (1982) reported that at $29^{\circ} \mathrm{C}$, Eucalyptus globulus was the highest isoprene emitter of the 54 species studied; isoprene emission from eucalypts is therefore likely to be high during the summer months.

\section{Quantification of Enclosure VOCs}

Emission measurements can be affected by the handling of plants during enclosure sampling (Winer et al. 1992). Although care was taken not to stress the plant or damage its foliage, and every plant was given time to reach a steady-state in its enclosure environment, the enclosure emissions in this study must be regarded as estimates. Enclosure by the method chosen may incur an increase in emission rates, but this error is likely to be far outweighed by the error from scaling emission rates to larger biomasses. Similar compounds were observed from the same genus; for example, all eucalypts emitted cineole and aromadendrene as major components. The species enclosure emissions are summarised in table 5.

The highest emission rates were from the understorey species Olearia phlogopappa and Correa lawrenciana. Understorey plants, as well as the larger eucalypt trees that dominate Australian vegetation, make a large contribution to the VOCs emitted into the atmosphere.

The two Tasmannia lanceolata samples were quite close together, representing only a $6.7 \%$ total VOC deviation. Running these samples consecutively did not allow for large variations in sampling conditions; temperature changed by $2^{\circ} \mathrm{C}$ and other conditions remained fairly constant. The average individual compound deviation was $31.1 \%$, indicating that the reproducibility was similar to the dual ambient air samples previously discussed.

\section{Biomass Data to Form Estimates over Larger Areas}

In the absence of species-specific biomass data, a collation of dry foliage biomass data from the literature (Cannell 1982) was used in conjunction with the averaged emission rates in this study to form an emission estimate. This allowed for the first time an estimate of the emission of total VOCs from the wet and dry sclerophyll forests of Tasmania. These results 
TABLE 5

The quantification of the enclosure emissions by the species studied ( $\mathrm{HC}=$ hydrocarbon)

\begin{tabular}{|c|c|c|c|c|c|}
\hline Species & $\begin{array}{c}\text { Total VOC } \\
\text { emission } \\
\left(\mathrm{g} \mathrm{g}^{-1}(w w) \mathrm{h}^{-1}\right)\end{array}$ & $\begin{array}{l}\text { Total HC } \\
\text { monoterpene } \\
\text { emission (\%) }\end{array}$ & $\begin{array}{c}\text { Total HC } \\
\text { sesquiterpene } \\
\text { emission (\%) }\end{array}$ & $\begin{array}{c}\text { Total oxygen-ated } \\
\text { VOC emission } \\
(\%)\end{array}$ & $\begin{array}{c}\text { Other } \\
\text { emission }(\%)\end{array}$ \\
\hline E. leucoxylon (day) & $4.53 \times 10^{-7}$ & 34 & 10 & 20 & 37 \\
\hline E. viminalis & $3.03 \times 10^{-7}$ & 33 & 16 & 49 & 2 \\
\hline E. johnstonii & $4.90 \times 10^{-7}$ & 4 & 3 & 68 & 25 \\
\hline E. leucoxylon (night) & $2.00 \times 10^{-7}$ & 38 & 15 & 38 & 9 \\
\hline P. squameum & $3.91 \times 10^{-7}$ & 76 & 20 & 1 & 3 \\
\hline E. impressa & $4.75 \times 10^{-8}$ & 47 & 31 & 6 & 16 \\
\hline T. lanceolata & $1.81 \times 10^{-7}$ & 44 & 12 & 21 & 23 \\
\hline T. lanceolata & $1.84 \times 10^{-7}$ & 19 & 29 & 37 & 15 \\
\hline O. phlogopappa & $5.43 \times 10^{-6}$ & 2 & 94 & 3 & 1 \\
\hline L. lanigerum & $3.73 \times 10^{-7}$ & 26 & 24 & 40 & 10 \\
\hline O. antennaria & $1.23 \times 10^{-7}$ & 4 & 12 & 43 & 42 \\
\hline C. lawrenciana & $2.79 \times 10^{-6}$ & 53 & 46 & 1 & 1 \\
\hline B. salicina & $3.61 \times 10^{-8}$ & 14 & 26 & 40 & 20 \\
\hline A. dealbata & $1.98 \times 10^{-8}$ & 3 & 0 & 59 & 38 \\
\hline P. apetala & $4.67 \times 10^{-8}$ & 53 & 5 & 14 & 27 \\
\hline Z. arborescens & $3.67 \times 10^{-7}$ & 3 & 71 & 25 & 1 \\
\hline
\end{tabular}

are shown in table 6 . Foliage biomass variations between eucalypt species, as reported in the literature, was equivalent to the variations within a species when measured under different conditions, so it was considered reasonable to average these values and note the associated error as shown in table 7.

The average emission rate for the three species of eucalypt sampled was $1.3 \times 10^{-7} \mathrm{~g} \mathrm{~g}^{-1}$ (wet weight) $\mathrm{h}^{-1}$ with a relative standard deviation of $37 \%$. This compares well to the winter emission rates of different Eucalyptus species found by $\mathrm{He}$ et al. (2000). An average emission rate for the Eucalyptus species sampled under various conditions was estimated. These conditions include temperature variations between $6^{\circ}$ and $14^{\circ} \mathrm{C}$, relative humidity variations from $56 \%$ to $86 \%$ and sunshine variation due to night-time and daytime sampling. The average emission rate of the understorey shrubs, which showed greater variation due to the diffuse phylogenetic relationships between the species sampled, was $7.8 \times 10^{-7} \mathrm{~g} \mathrm{~g}^{-1}$ (ww) $\mathrm{h}^{-1}$ with a relative standard deviation of $201 \%$.

The standard deviations from the average foliage biomass and the average emission rates, together with the error arising from the sampling procedure already outlined, suggest that the error could be as great as $300 \%$ for the understorey emission estimates and $150 \%$ for the eucalypt emission estimates.

\section{Relationships between Oil Concentration and Emission of VOCs}

Because of the noted intra-species variation in the literature, the oil was isolated from the leaves of the plant sampled in the enclosure experiments (Boland et al. 1991). The composition of the oils of the following species have been identified in the literature: Olearia phlogopappa (Dragar et al. 1988), Tasmannia lanceolata (Southwell \& Brophy 1992), Eucalyptus viminalis (Boland et al. 1991), E. jobnstonii (Boland et al. 1991), Phebalium squameum (Ghisalberti
1998), Leptospermum lanigerum (Brophy et al. 1999) and Zieria arborescens (Flynn \& Southwell 1987).

Of the 13 oil analyses of enclosure samples, 10 showed linear relationships that suggest emission rates can be estimated from the oil of some species if the environmental conditions are suitable. Different species would have different linear relationships berween their oil component concentrations and the amount volatilised because of different oil gland abundances, sizes and leaf surface areas. The small number of VOCs that correlated in some of the essential oils and their emissions may explain why three analyses did not follow this trend. Some of the VOCs would have been below the detection limit of the GC-MS. Also, only the hydrocarbons and the smaller oxygenated hydrocarbons were observed in the enclosure emissions due to their higher volatilities than the other VOCs present in the oil.

The trendlines passed through the origin; table 8 lists the trends for the different species and the $\mathrm{R}^{2}$ values. With greater concentrations for the oil compositions and larger air samples taken for the enclosure samples, the minor oil constituents would be included, which would give a better representation of the trends.

Our results conflict with those of Schindler \& Kotzias (1989), who found no relationship between monoterpene volatilisation and leaf oil composition in conifers. This inconsistency may be due to the solvent extraction from charcoal method that they used for VOC trapping which had only an $85 \%$ recovery of emitted VOCs. Also, it is possible that the conifers have different biological mechanisms for releasing VOCs from their leaves as opposed to the species used in this study.

VOC emission appears to be limited by factors controlling the vapour-phase concentrations within the leaves, including liquid-phase concentration and vapour pressure (Evans $e t$ al. 1982). This helps to explain the inconsistencies found in this study. Hanover (1972) has shown a general correspondence between the volatiles present in oleoresin extracts and those present in the ambient air surrounding 
TABLE 6

The emission of total VOCs from vegetative areas in kilograms per hour for eucalypts and understorey species in eucalypt forest

\begin{tabular}{lcc}
\hline Vegetation type & $\begin{array}{c}\text { Emissions of total VOCs from this vegetation (kg per hour) } \\
\text { uncalypts }\end{array}$ & $\begin{array}{c}\text { understorey shrubs } \\
\text { Total dry sclerophyll in Tasmania }\end{array}$ \\
Total wet sclerophyll in Tasmania & 1200 & 4200 \\
Total sclerophyll in Tasmania & 600 & 2200 \\
Eucalyptus reserves in Hobart Air Shed & 1700 & 6400 \\
Total Tasmanian sclerophyll forest scaled down to Hobart Air Shed & 13 & 46 \\
\hline
\end{tabular}

TABLE 7

Average of foliage biomass and errors obtained from the literature for Eucalyptus species and the understorey shrubs of eucalypt forests

\begin{tabular}{lccc}
\hline Vegetation type & Dry foliage biomass $\left(\mathrm{t} \mathrm{ha}^{-1}\right)$ & Number of experiments & Relative standard deviation \\
\hline Eucalyptus species & 4.9 & 32 & 49.7 \\
Understorey shrubs & 3.1 & 5 & 43.9 \\
\hline
\end{tabular}

Pinus monticola. However, there were quantitative differences that appeared to be related to vapour-pressure differences.

Table 8 shows that the coefficients of the equations vary significantly. This value would vary within each species depending on the conditions. Further work is needed to elucidate the controls on the mechanism that manipulates the release of volatiles. The gradients were typically below unity, which may suggest mechanisms to conserve leaf oil were operating. Interspecies differences are attributable to the leaf's surface area to volume ratios and other physiological variations such as gland size, structure and the mechanism by which the plant regulates the passage of VOCs from within the oil glands to the atmosphere.

\section{CONCLUSIONS}

\section{Ambient Air Analysis}

- The typical components and concentrations of VOCs in six environments with minimal anthropogenic disturbance were found. Monoterpenes were the majority of the biogenic VOCs and isoprene was not found in the low-temperature ambient air samples taken.

- A positive correlation between VOC emission and air temperature was found. The characteristic emission factor was determined for the Chalet site. The functions describing the air concentrations of eight compounds at the Chalet site were found. The similarity of these functions may be typical of biogenic compounds in air.

- This study outlines the basal VOC air concentration taken over the winter months; samples taken over summer would complement these low-concentration data. As the main components in ambient air samples have been identified, standards could be prepared in future studies for the main VOCs present, reducing the error involved with the standard function used in this study.

- The solid-phase microextraction method used proved too insensitive for the ambient air analysis in this study. It could have future uses in enclosure studies where the concentrations are larger, or as a substitute for hydrodistillation in the analysis of VOCs in the leaves of plants.

- Suburban air contained many straight-chain alkanes, aldehydes and ketones, suggesting these are not biogenically produced or are from introduced species.

\section{Enclosure and Oil Analyses}

- The VOCs emitted from 13 Tasmanian native species and one introduced species (Eucalyptus leucoxylon) were ascertained and their emission rates determined.

- An emission estimate for the eucalypt forest in Tasmania and for the Hobart Air Shed indicated that understorey shrubs emit more VOCs than do the eucalypts.

- A general linear trend was found between the oil concentration and emission rates of plants, suggesting that emission rates might be predicted from the literature or hydro-distillation.

\section{ACKNOWLEDGEMENTS}

This work was partly supported by the Department of Primary Industries, Water and the Environment in conjunction with the National Pollution Inventory Project of Environment Australia. We thank Barry Windridge and Michael Wall for their financial assistance and the use of resources; the School of Chemistry at the University of Tasmania for financial assistance; and Tasmanian Herbarium staff for identifying all the species sampled. The Central Science Laboratory, in particular Noel Davies, provided information on the separation of VOCs using multiadsorbent cartridge adsorption/thermal desorption by GCMS. 
TABLE 8

Suggested trends from oil/emission graphs for the species studied

\begin{tabular}{|c|c|c|c|c|}
\hline Species & Equation of Trend $\mathrm{Y}=$ & $\mathrm{R}^{2}$ Value & Number of data points & $\mathrm{R}^{2}$ value suggests trend \\
\hline O. phlogopappa & $0.0492 \mathrm{x}$ & 0.85 & 7 & Yes \\
\hline T. lanceolata & $0.0059 x$ & 0.96 & 6 & Yes \\
\hline E. viminalis & $0.0169 x$ & 0.82 & 11 & Yes \\
\hline E. johnstonnii & $21.4 \mathrm{x}$ & 1 & 6 & Yes \\
\hline Z. arborescens & $0.0006 \mathrm{x}$ & 0.75 & 7 & Yes \\
\hline P. apetala & $0.289 \mathrm{x}$ & 0.74 & 8 & Yes \\
\hline P. squameum & $0.0348 \mathrm{x}$ & 0.48 & 8 & Yes \\
\hline L. lanigerum & $0.0699 x$ & 0.81 & 10 & Yes \\
\hline O. antennaria & $0.0042 \mathrm{x}$ & 0.00 & 4 & No \\
\hline A. dealbata & $0.0037 \mathrm{x}$ & 0.00 & 3 & No \\
\hline B. salicina & $18.5 x$ & 1 & 3 & Yes \\
\hline C. lawrenciana & $0.931 x$ & 0.90 & 13 & Yes \\
\hline
\end{tabular}

\section{REFERENCES}

Alonzo, G., Del Bosco, S., Fatria, S., Palazzolo, E., Saiano, F. \& TUSA, N., 2000: Citrus hybrid leaf essential oil. Flavour and Fragrance Journal 15(2): 91-95.

Andreani-Aksoyoglu, S. \& Keller, J., 1995: Estimates of monoterpene and isoprene emissions from the forests in Switzerland. Journal of Atmospheric Chernistry 20: 71-87.

Arnold, M., Kuusisto, S. \& Mroueh, U., 1998: Inventory of emissions of volatile organic compounds (VOC) in 1996. Technical Research Centre of Finland 1921: 1-35.

Ayers, G. \& Gillett, R., 1988: Isoprene emissions from vegetation and hydrocarbon emissions from bushfires in tropical Australia. Journal of Atmospheric Chemistry 7: $177-190$.

Betrs, T.J., 2000: Solid Phase Microextraction of volatile constituents from individual fresh Eucalyptus leaves of three species. Planta Medica 66: 193-195.

Boland, D., Brophy, J. \& House, A., 1991: Eucalyptus Leaf Oils; Use, Chemistry, Distillation and Marketing. ACIAR/ CSIRO, Sydney.

Brophy, J.J., Goldsack, R.J., Bean, A.R., Forster, P.I. \& Lepschi, B.J., 1999: Leaf essential oils of the genus Leptospermum (Myrtaceae) in eastern Australia. Part 3. Leptospermum arachnoides and allies. Flavour and Fragrance Journal 14: 85-91.

Cannell, M.G.R., 1982: World Forest Biomass and Production Data. Academic Press, London.

CAO, X.L. \& HewitT, C.N., 1994: Study of the degradation by ozone of adsorbents and of the hydrocarbons adsorbed during the passive sampling of air. Environmental Science and Technology 28: 757-762.

Crouteau, R., 1987: Biosynthesis and catabolism of monoterpenoids. Chemical Reviews 87: 929-954.

Dragar, V.A., Menary, R.C. \& Dragar, C., 1988: A New Oil from the Tasmanian Endernic Olearia Species. Developments in Food Science: Flavours and Fragrances 18: 21-32.

DPIWE (Department of Primary Industries, Water and the Environment), 1998: National Pollutant Inventory Guide, DPIWE, Hobart.

Evans, R., Tingey, D., Gumpertz, M. \& Burns, W., 1982: Estimates of isoprene and monoterpene emission rates in plants. Botannical Gazette 143: 304-310.

Fehsenfeld, F., Calvert, J., Fall, R., Goldan, P., Guenther, A., Hewitt, C., Lamb, B., Liu, S., Trainer, M., WestberG, H. \& ZimMERMAN, P., 1992: Emissions of volatile organic compounds from vegetation and the implications for atmospheric chemistry. Global Biogeochemical Cycles 6: 389-430.
FLYNN, T.M. \& SOUTHWELL, I.A., 1987: Essential oil constituents of the genus Zieria. Phytochernistry 26: 1673-1686.

Galbally, I., Meyer, C., Ye, Y., Bentley, S., Carpenter, L. \& Monks, P., 1994-1995: Ozone, nitrogen oxides (NOx) and volatile organic compounds in near suface air at Cape Grim. Baseline Atmospheric Program (Australia): 81-88.

GhisalberTi, E.L., 1998: Phytochemistry of the Australian rutaceae: Boronia, Eriostemon and Phebalium species. Phytochemistry 47: 163-176.

Gomez, O. \& Baldasano, J.M., 1999: Biogenic VOC emission inventory for Catalonia, Spain. Transport and Chemical Transformation in the Troposphere 2: 109-115.

GUENTHER, A., 1997: Seasonal and spatial variations in natural volatile organic compound emissions. Ecological Applications 7: 34-45.

Guenther, A., Monson, R. \& Fall, R., 1991: Isoprene and monoterpene emission rate variability: Observations with Eucalyptus and emission rate algorithm development. Journal of Geophysical Research 96: 10799-10808.

Guenther, A., Zimmerman, P. \& Wildermuth, M., 1994: Natural volatile organic compound emission rate estimates for United States woodland landscapes. Atmospheric Environment 28: 1997-1210.

Guenther, A., Hewitt, C., Erickson, D., Fall, R., Geron, C., Graedel, T., Harley, P., Klinger, L., McKay, W., Pierce, T., Scholes, B., Steinbrecher, R., Thallamraju, R., TAYLoR, R. \& Zimmerman, P., 1995: A global model of natural volatile organic compound emissions. Journal of Geophysical Research 100(D5): 8873-8892.

Guenther, A., Zimmerman, P., Klinger, L., Greenberg, J., Ennis, C., Davis, K., Pollock, W., Westberg, H., AlLWINE, G. \& GERON, C., 1996: Estimates of regional natural volatile organic compound fluxes from enclosure and ambient measurements. Journal of Geophysical Research 101(D1): 1345-1359.

HANOVER, J.S., 1972: Factors affecting the release of volatile chemicals by forest trees. Mitteilungen Forstlichen BundesVersuchanst Wien 97: 625-644.

He, C.; Murray, F. \& Lyons, T., 2000a: Monoterpene and isoprene emissions from 15 Eucalyptus species in Australia. Atmospheric Environment 34: 645-655.

He, C.; Murray, F. \& Lyons, T., 2000b: Seasonal variations in monoterpene emissions from Eucalyptus species. Chemosphere: Global Change Science 2: 65-76.

Hendricks, H., Malungre, T., Batterman, S. \& Bos, R., 1978: The essential oil of Cannibis sativa leaves. Pharnaceutisch Weekblad 113(17): 413-24.

HewitT, C. \& StreEt, R., 1992: A qualitative assessment of the emission of non-methane hydrocarbons compounds from 
the biosphere to the atmosphere in the U.K.: Present knowledge and uncertainties. Atmospheric Environment 26A: 3069-3077.

Isidorov, V., JaroszynskA, J., SaCharewicz, T. \& PrIozNIKowy, E., 1999: Natural VOC emissions from forests in Poland. Atmospheric Environment 33: 4739-4744.

ЈАСОВ, D.J. \& WOFSY, S.C., 1988: Photochemistry of biogenic emissions over the Amazon forest. Journal of Geophysical Research 93(D2): 1477-1486.

Kesselmeier, J. \& StaudT, M., 1999: Biogenic volatile organic compounds (VOC): An overview on emission, physiology and ecology. Journal of Atmospheric Chemistry 33: 23-88.

Kesselmeier, J., Kuhn, U., Wolf, A., Andreae, M.O., Ciccioli, P., Brancaleoni, E., Frattoni, M., Guenther, A., GreenberG, J., Vasconcellos, P.D., de Olrvia, T. \& Tavares, T., 2000: Atmospheric volatile organic compounds (VOC) at a remote tropical forest site in central Amazonia. Atmospheric Environment 34: 40634072

Kirstine, W., Galbally, W. I., Ye, Y. \& Hooper, M., 1998: Emissions of volatile organic compounds (primarily oxygenated species) from pasture. Journal of Geophysical Research 103(D9): 10605-10619.

Konig, G., Brunda, M., Puxbaum, H., Hewttt, C., Duckham, S. \& Rudolph, J., 1995: Relative contribution of oxygenated hydrocarbons to the total biogenic VOC emissions of selected mid-European agricultural and natural plant species. Atmospheric Environment 29: 861874.

Kreuzwieser, J., Schnitzler, J.P. \& Steinbrecher, R., 1999: Biosynthesis of organic compounds emitted by plants. Plant Biology 1: 149-159

LINDFORS, V. \& LAURILA, T., 2000: Biogenic volatile organic compound (VOC) emissions from forests in Finland. Boreal Environment Research 5: 95-113.

Loretto, F., Ciccioli, P., Cecinato, A., Brancaleoni, E., Frattoni, M., Fabozzi, C. \& Tricoli, D., 1996a: Evidence of the photosynthetic origin of monoterpenes emitted by Quercus ilex L. leaves by $13 \mathrm{C}$ labelling. Plant Physiology 110: 1317-1322.

Loretto, F., Ciccioli, P., Cecinato, A., Brancaleoni, E., Frattoni, M., Fabozzi, C. \& Tricoli, D., 1996b: Influence of environmental factors and air composition on the emission of alpha-pinene from Quercus ilex leaves. Plant Physiology 110: 267-275.

Mann, J., 1987: Secondary Metabolism. Clarendon Press, Oxford.

MasadA, Y., 1976: The Analysis of Essential Oils by Gas Chromatography and Mass Spectrometry. Wiley Publishers, New York.

Monson, R., Lerdau, M., Sharkey, T., Schimel, D. \& Fall, R., 1995: Biological aspects of constructing volatile organic compound emission inventories. Atmospheric Environment 29: 2989-3002.

MULLER, J., 1992: Geographical distribution and seasonal variation of surface emissions and deposition velocities of atmospheric trace gases. Journal of Geophysical Ressearch 97: 3787-3804

Muraleedharan, T.R., Radojevic, M., Waugh, A. \& Caruana, A, 2000: Chemical characterisation of the haze in Brunei Darussalam during the 1998 episode. Atmospheric Environment 34: 2725-2731

Pankow, J.F., Luo, W., Isabelle, L., Bender, D. \& Baker, R., 1998: Determination of a wide range of volatile organic compounds in ambient air using multisorbent adsorption/ thermal desorption and gas chromatography/mass spectrometry. Analytical Chemistry 70: 5213-5221.
Pio, C., Nunes, T. \& Valente, A., 1997: Forest emissions of hydrocarbons. Transport and Chemical Transformation in the Troposphere 4: 335-341.

Reid, J., Hill, R., Brown, M. \& Hovenden, M. (Eds.), 1999: Vegetation of Tasmania. Australian Biological Resources Study, Hobart.

SCHINdlek, T. \& Kotzias, D., 1989: Comparison of monoterpene volatilization and leaf oil composition in conifers. Naturwissenschaften 76: 475-447.

Schomburg, G., 1990: Gas Chromatography: a Practical Course. VCH Publishers Inc., New York.

SeEdS, M.A., 1999: Foundations in Astronomy. Brooks/Cole Publishing Company, London.

Sharkey, T.D. \& LoReTto, F., 1993: Water stress, temperature, and light effects on the capacity for isoprene emission and photosynthesis of kudzu leaves. Oecologia 95: 328333.

SOUTHWELl., I.A. \& BRophy, J., 1992: Differentiation within the Australian Tasmannia by essential oil comparison. Phytochemistry 31: 3073-3081.

Staudt, M., Bertin, N., Hansen, U., Seufert, G., Ciccioli, P., Foster, P., Frenzel, B. \& Fugit, J.L., 1997: Seasonal and diurnal patterns of monoterpene emissions from Pinus Pinea (1.) under field conditions. Atmospheric Environment 31: 145-156.

Steinbrecher, R., Hauff, K., Rabong, R. \& Steinbrecher, J., 1997: Isoprenoid emission of oak species typical for the Mediterranean area: source strength and controlling variables. Atmospheric Environment 31: 79-88.

Street, R.A., Hewitt, C.N. \& Mennicken, S., 1997: Isoprene and monoterpene emissions from a eucalyptus plantation in Portugal. Journal of Geosphysical Research 102(D13): 15875-15887.

Wellington Park Management Trust, 1996: Wellington Park values, use and management inventory for public comment. Wellington Park Management Trust, Hobart, p. 272.

Wedel, A., Muller, K., Ratte, M. \& Rudolph, J., 1998: Measurement of volatile organic compounds (VOC) during POPCORN 1994: Applying a new on-line GCMS technique. Journal of Atmospheric Chemistry 31:73103.

WENT, F., 1960: Blue haze in the atmosphere. Nature 187: 641643.

Winer, A., Arey, J., Atkinson, R., Aschmann, S., Long, W., Morrison, C. \& OlszYK, D., 1992: Emission rates of organics from vegetation in California's Central Valley. Atmospheric Environment 26A: 2647-2659.

YassaA, N., Meklati, B.Y. \& Cecinato, A., 2000: Evaluation of monoterpenic biogenic volatile organic compounds in ambient air around Eucalyptus globulus, Pinus halepensis and Cedrus atlantica trees growing in Algiers city area and achiral capillary gas chromatography. Atmospheric Environment 34: 2809-2816.

Zimmerman, P., 1979: Determination of Emission Rates of Hydrocarbons from Indigenous Species of Vegetation in the Tampa/St. Petersberg, Florida Area. U.S. Environment Protection Agency. Research Triangle Park, North Carolina

(accepted 9 December 2002) 